\title{
Passive Experiments for Monitoring Mining Operations by Dragline at Kuzbass Open Pits - Estimation of Coal Losses
}

\author{
Alexei Selyukov ${ }^{1, *}$, and Kirill Byrdin ${ }^{1}$ \\ ${ }^{1}$ T.F. Gorbachev Kuzbass State Technical University, Department of open pit mining, 650000 \\ Kemerovo, 28 Vesennya st., Russia
}

\begin{abstract}
The natural conditions for the formation of coal deposits in different regions of the globe are the same, all of them belong to reservoir sedimentary deposits and differ only in the degree of metamorphism and tectonic disturbances. In this regard, coal deposits of the Kuznetsk basin (Kuzbass, Western Siberia, Russia)) that have no analogues in nature are unique. Here are all sorts of options for the occurrence of coal seams both in terms of their thickness, dip angle, number, and the degree of disturbance by plicative and disjunctive disturbances. The article presents some results of research on ways to reduce coal losses in open pit mining during its extraction by draglines. The study was carried out on the example of deposits in Kemerovo region with coal seams in an inclined and steep formations, which allows analyzing the possibilities of applying the proposed technological solutions in the widest range of specific mining and geological conditions.
\end{abstract}

\section{Introduction}

A comprehensive justification of development options for resource-saving technologies for open pit mining of Kuzbass coal deposits, focused on maximum coal extraction, in relation to existing quarry fields, including abandoned open pit mines, as well as promising deposits, should be considered timely. Technological solutions developed by Russian [1-6] and foreign [7-9] scientists are designed to enhance the technical and economic efficiency of open pit mining while reducing coal losses in Kuzbass. Reducing coal losses during mining operations by dragline in a coal-and-overburden stope is an important aspect of improving coal production efficiency. Field observations (passive experiment) of the process of mining draglines at the Kedrovsky, Chernigovsky, and Sartaki open pits revealed the following sources of coal losses: cleaning the roof and soil of the seam, in a triangle of not scooping, the breaking by dragline bucket, spillage and blasting.

\footnotetext{
* Corresponding author: sav.ormpi@,kuzstu.ru
} 


\section{Materials and Methods}

To simplify the organization of mining transport equipment during open pit mining operations and reduce mining costs, it is advisable to use draglines. To this end, the mining process of dragline was investigated. Based on field observations (Kedrovsky and Chernihiv open pits in the Northern Kuzbass), the process of developing excavation layers when dragline's scooping with lower digging was studied (see Fig. 1-3).

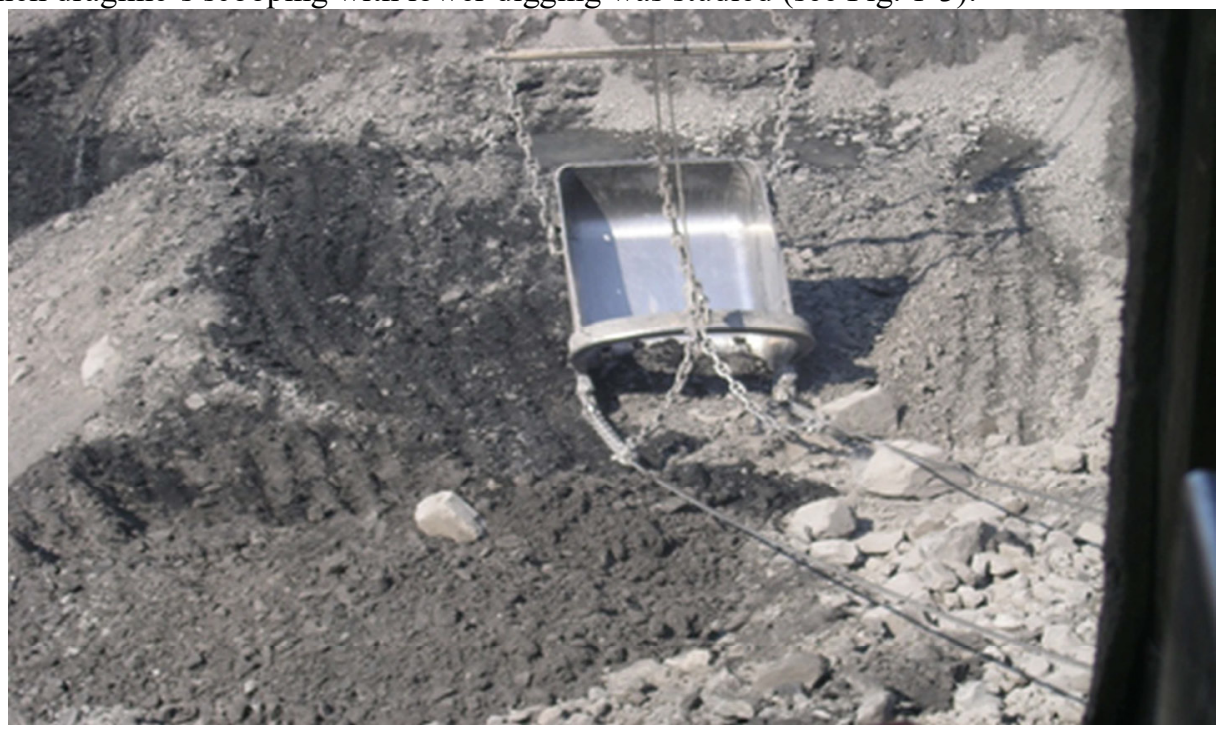

Fig. 1. Scraping the roof of the seam with dragline ESh10.70 at the Sartaki open pit, Central Kuzbass.

The sequence of work is as follows. After removing the rock overburden, the dragline proceeds to directly stripping the seam's roof by removing the rock layer. The exploded arched layer is removed as follows. Depending on where the excavation is started (at a distance equal to or less than the radius of the dragline), the bucket is lowered onto the cleared area vertically or at an angle to the horizontal. Furrowing teeth on the rock and crashing into it, the bucket lies on the bottom. Further filling with the rock occurs due to its movement. In this case, the excavator driver can adjust the thickness of the removed chips, changing the position of the bucket.

The tracks left after the bucket's pass are relatively smooth surfaces, since the coal and rock loosened by the teeth are smoothed by its bottom (see Fig. 3). A surface with tooth marks is observed where the bucket is lowered vertically onto the cleared area (see Fig. 2). When removing the arched layer of rock between the passages, rock crests remain, which are cut off during repeated movements of the bucket. Initially, the rock is removed without disturbing the formation by the teeth of the bucket. With a decrease in the thickness of the removed rock layer, the teeth penetrate into the formation, destroying its upper part. Then the main part of the reservoir is cleaned, contoured and cleaned. 


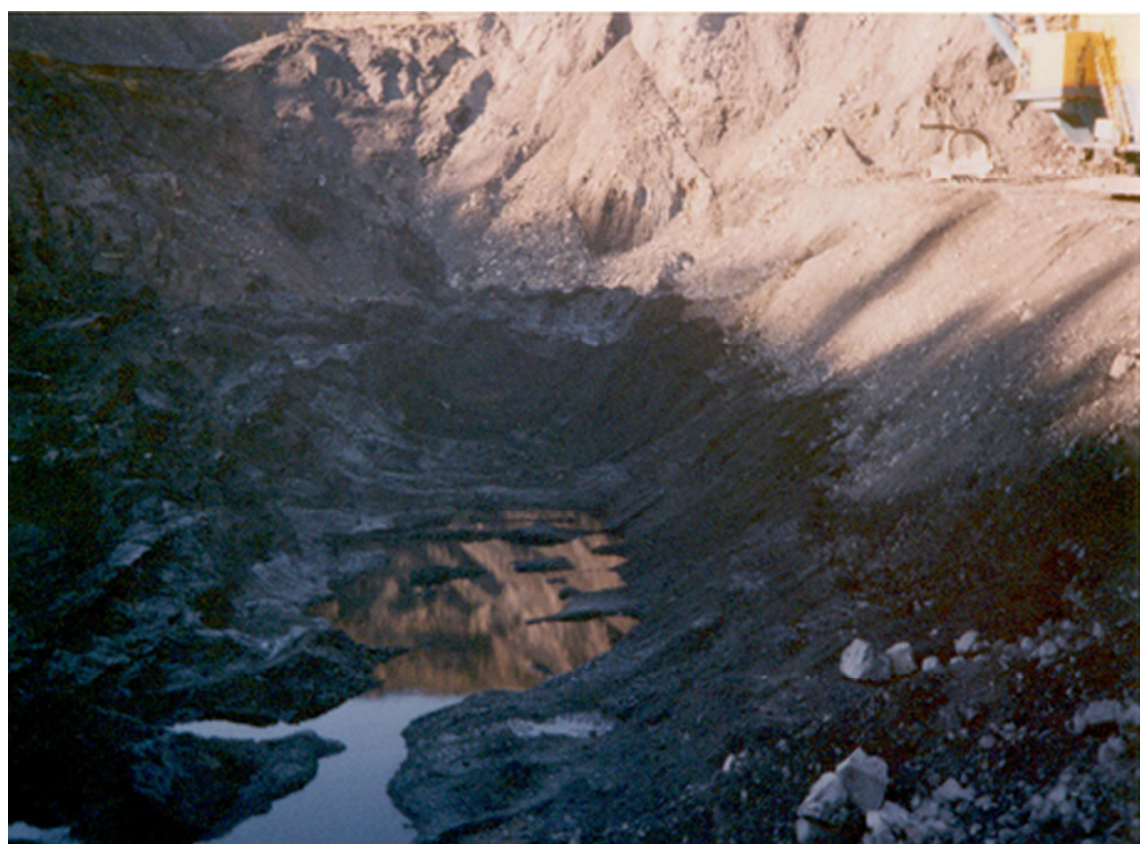

Fig. 2. Type of coal mining face when developing with dragline ESh10.70 in the Kedrovsky open pit (Northern Kuzbass) - the section of the Latyshevsky site.

In the face, the dragline is installed so that the traction rope does not rub on the upper edge of the slope of the face. This requirement is due to the safety of the traction rope. It is necessary to take into account the boundaries of the self-unloading zone of the bucket, especially when mining the far part of the face. With an increase in the depth of digging, the broach of the loaded bucket increases to withdraw it from the self-unloading zone. If the last coal layer is excavated in the soil of the seam during prolonged drawing of the loaded bucket, it is possible to clog the coal with rock. Therefore, the driver needs to work with a lifting and traction rope, that is, to control the movement of the bucket.

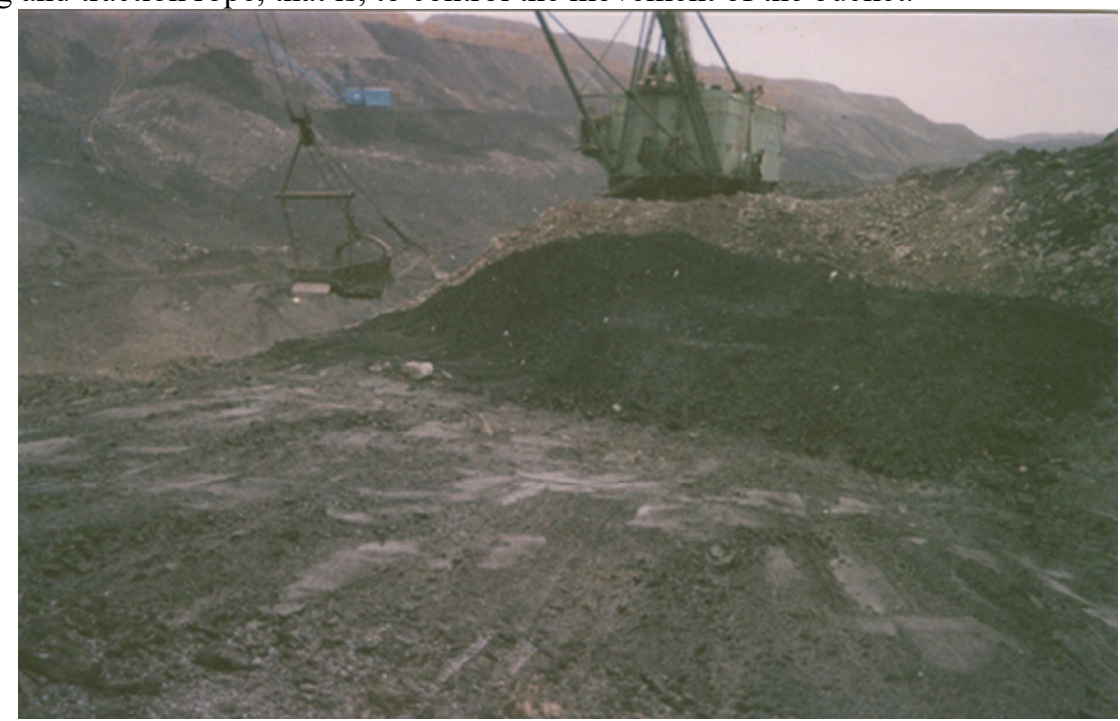

Fig. 3. Filling the bucket of the dragline ESh10.70 with coal during the development of the Volkovsky layer at the Chernigov section, the Chernihiv field. 


\section{Results and Discussion}

It is necessary to use such a method of work as bulldozing the breed of prism drags (or "tightness"). To do this, the loaded bucket is pulled to the dragline by the value of the length of the harness. Then they begin to lift it with a pulling rope and when pumping a loaded bucket back into the face, its rear wall acts as a dump of a bulldozer. When working out the near layers of the notch (with respect to the dragline), controlled digging is used; the loaded bucket is not brought by 1.5-2 $\mathrm{m}$ to the edge line of the slope of the bottom and at this moment the traction rope is first braked and then released after stopping the bucket. After the loaded bucket is pumped back (pendulum principle), the bucket is raised. With this method of operation, the drawing prism (consisting of coal) "settles" on the face plane and almost does not form a "tightness" of coal on the working platform, which reduces the likelihood of clogging of coal by the rock during the formation of spills when the excavator bucket moves to the dump truck and during loading.

With a small thickness of the coal layer at the stage of completion of the formation (less than one meter), digging of coal two or three times is performed to fill the bucket, which increases the cycle time. Observations of the mining process of the rock-and-coal block allowed us to draw the main conclusion on the dragline mining technology. It consists in the fact that when excavating a rock-and-coal block, it is necessary to actively manage digging operations and the dragline working stroke. In this case, it is necessary to take into account the requirements of the traction rope in conjunction with the conditions of occurrence of a coal seam. The control of the dragline's stroke consists in choosing the step length, which should be determined in each case.

The loss parameters can be estimated in detail by the process of formation of the drawing prism, i.e. according to the geometrical parameters of the excavating layers (see Fig. 4).

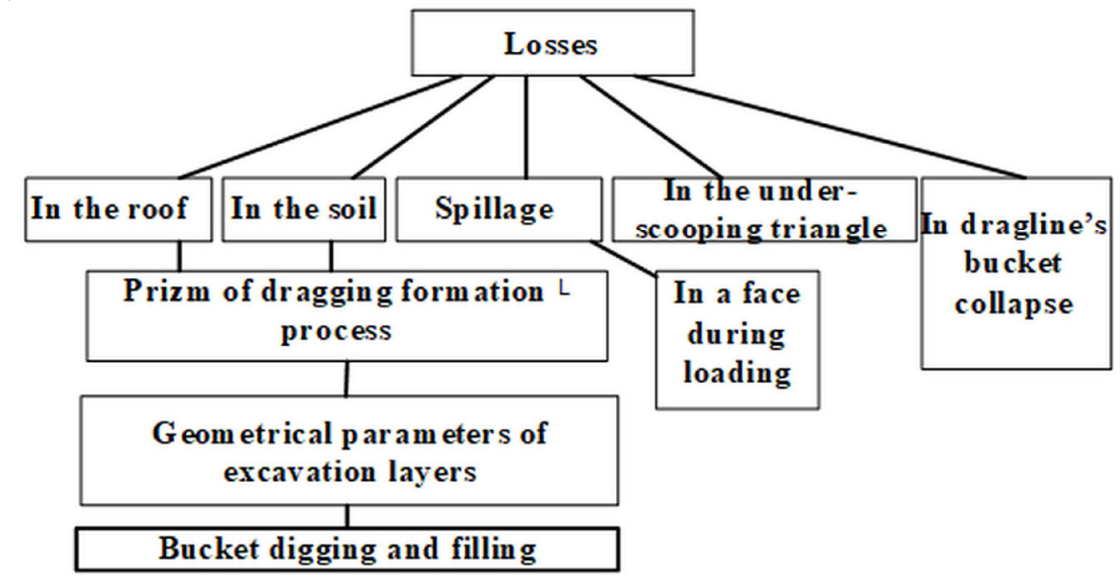

Fig. 4. A logical diagram of the sequence of estimation and parameters of operational losses of coal during mining operations by dragline.

Fig. 5. The sources of losses are presented in detail. When cleaning the rock above the top of the formation after the passage of the dragline bucket through the rock-and-coal contact, rock ridges remain (see Fig. 5.a), the height of which is equal to half of the tooth's height $\left(T_{h}\right)$. Further, crashing into the coal seam (see Fig. 5b), the rock ridges are mixed with the coal seam and this will be the source of losses in the seam roof. Then the main part of the formation is cleaned in this case, coal losses will be formed as a result of spillage in the face and during loading. These losses can be avoided if applying a technique such as shaking the dragline bucket in the face. The next source of loss will be coal ridges (see Fig. 
5) remaining after inserting and filling the bucket of a dragline above the soil of the coal seam, which, when further inserted into the contact, the rock-and-coal will certainly mix with the rock located under the soil of the coal seam.

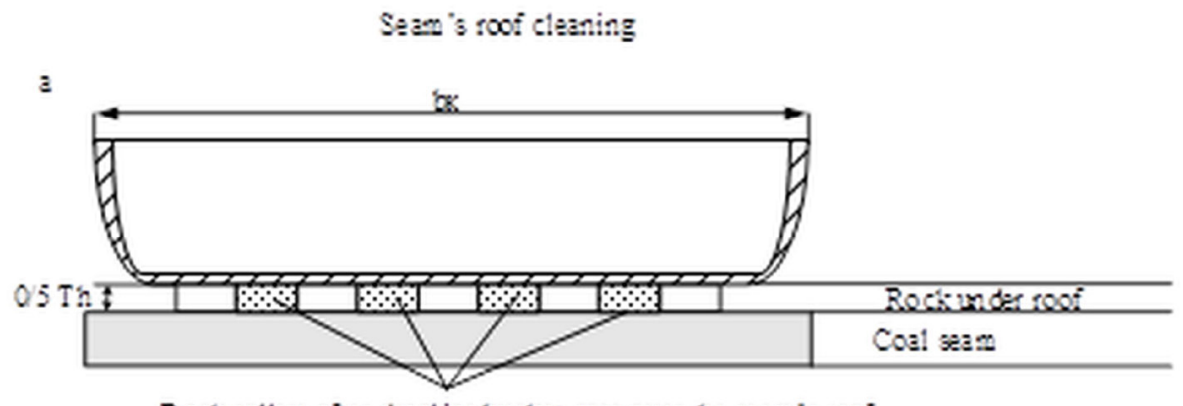

Rockrolters after dragl ine bucket pass over the san"s root

b
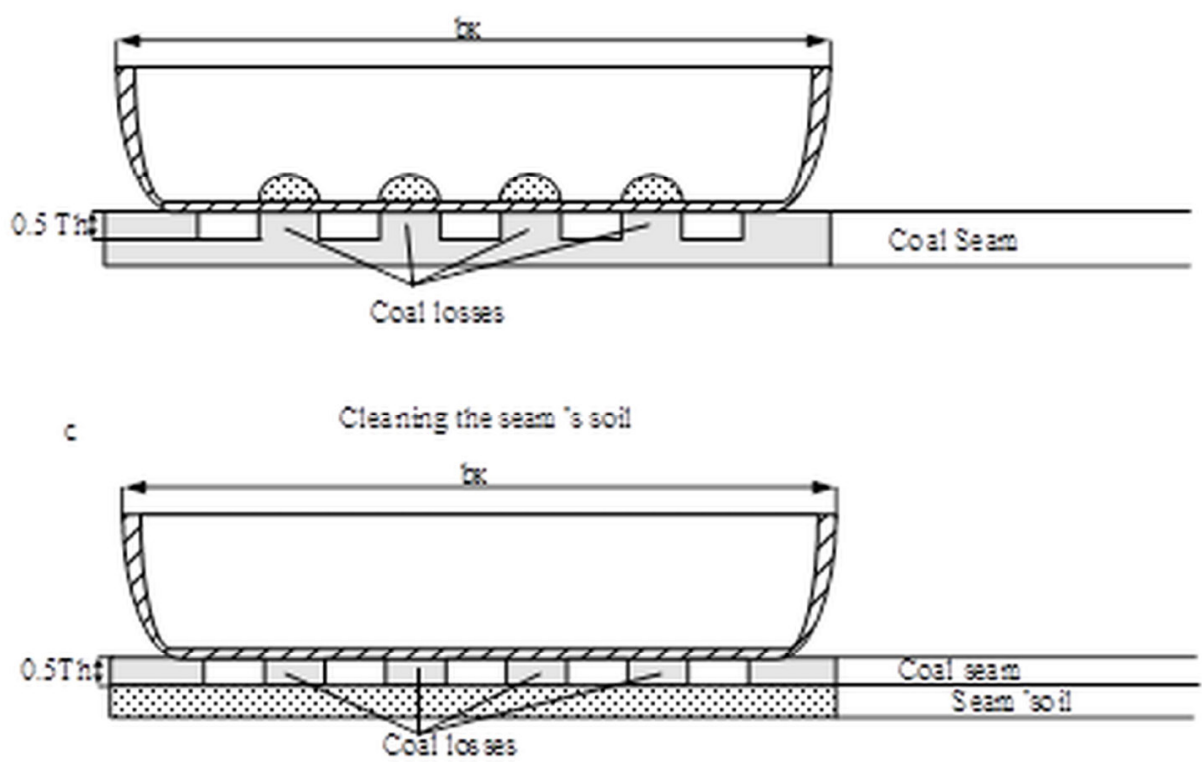

Fig. 5. Insert of a dragline bucket: a) digging cycle to remove rock above the seam's roof directly at the rock-and-coal contact; $b$ ) digging cycle along the formation at the half of the height of the teeth of the dragline bucket $\left(T_{h}\right)$ for cleaning the rock rollers; c) digging cycle for coal-and-rock contact in the soil of the seam. 

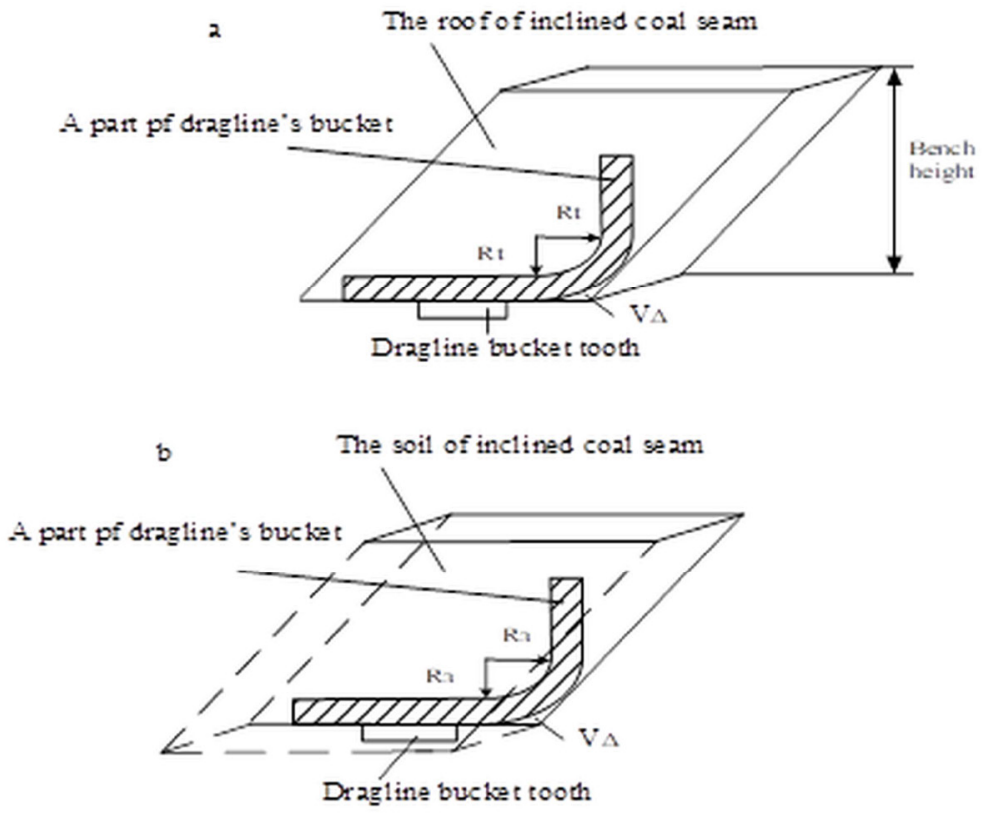

$\varepsilon$

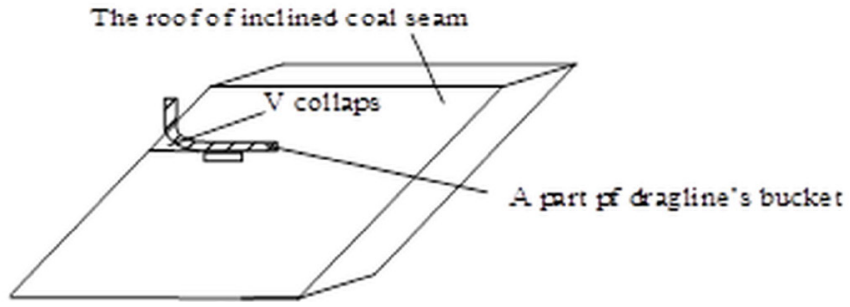

Fig. 6. Insert of dragline bucket: a) insert of dragline bucket in the coal-and-rock contact zone in the area of the rock slope; b) the same in the soil of the seam; c) coal losses as a result of a collapse of a dragline bucket.

The general view of the coal losses in the face is shown in Fig. 7.

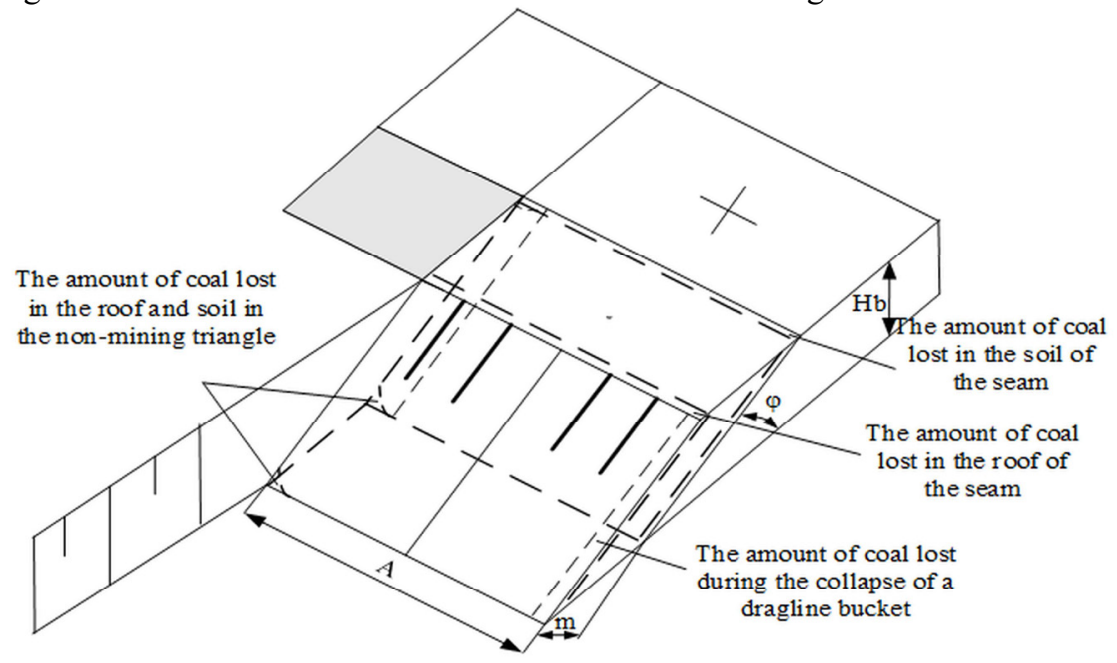

Fig. 7. General view of the sources of losses during the development of a coal seam with dragline. 


\section{Conclusions}

We found that coal losses increase with an increase in dragline bucket capacity, ledge height, and a decrease in the seam thickness, and for specific conditions differing in the constancy of the formation thickness and the angle of its occurrence. Coal losses range from 6 to $12 \%$ in mining operations with dragline.

\section{References}

1. M. A. Tyulenev, S. O. Markov, M. A. Gasanov, S. A. Zhironkin, Geotech. Geol. Eng., 36:5, 2789-2797 (2018)

2. A. V. Selyukov, Bulletin of the Tomsk Polytechnic University, Geo Assets Engineering, 326:12, 60-71 (2015)

3. O. Litvin, M. Tyulenev, S. Zhironkin, S. Prokopenko, Acta Montanistica Slovaca, 22:2, 146-152 (2017)

4. A. V. Selukov, Taishan Academic Forum - Project on Mine Disaster Prevention and Control, 156-160 (2014)

5. M. Tyulenev, O. Litvin, S. Zhironkin, M. Gasanov, Acta Montanistica Slovaca, 24:2, 8897 (2019)

6. A. Selyukov, V. Ermolaev, I. Kostinez, E3S Web Conf., 21, 01027 (2017)

7. H. Pavolová, S. Khouri, M. Cehlár, L. Domaracká, M. Puzder, Metalurgija, 55:4, 712714 (2016)

8. M. Tyulenev, S. Markov, M. Cehlar, S. Zhironkin, M. Gasanov, Acta Montanistica Slovaca, 23:4, 368-377 (2018)

9. M. Tyulenev, O. Litvin, M. Cehlár, S. Zhironkin, M. Gasanov, Acta Montanistica Slovaca, 22:3, 296-302 (2017) 